\title{
Experiment Study on Yield Stress Using Curve Extension Method and Vane Method
}

\author{
Fuyan Lyu, Ningxiao Zhang, Kai Zong, Chengdong Ao, Haoxue Di, Miao Wu \\ Mechanical Electronic and information engineering, \\ China University of Mining and Technology(Beijing), \\ 100083, Beijing
}

\begin{abstract}
The yield stress is a key rheological parameter of thick paste and critical design parameter of the high pressure pipeline system. Take coal slurry as an example, whether using vane method or curve extension method, the yield stress both exponentially increase with concentration increasing, but the data of yield stress in two methods is different. For pipes with different diameters, the yield stress showed in pipeline transportation varies during the extension of rheology curves. By contrasting the results of curve extension method and vane method using pipelines with different diameters, it comes that with a certain concentration and a certain range of diameter, yield stress with vane is bigger than that with curve extension, due to the effect of wall slip in pipe flow test.
\end{abstract}

Keywords-thick paste; yield stress; curve extension method; vane method; extend flow curve

\section{INTRODUCTION}

High concentrations and viscous solid wastes refer to solid-liquid two-phase wastes or byproducts with high solid content, viscosity, and fine grain size, which are produced in industry and municipal sewage treatment processes. Suspensions are also prevalent in a number of natural settings such as debris flow, lava flow, and flood waves carrying extremely high concentration of sediments. The yield stress is a key rheological parameter of thick paste and critical design parameter of a high pressure pipeline system[1], but the parameters is inaccurate obtained by the experiment [2], and now the opinions about how to get the yield stress are different[3-6]. Generally, dynamic yield stress is defined as the intersection of flow curve extension and shear stress axis [7].

The pipeline transportation experiment is complex with large difficulties. The conditions are similar with the project, so it was more reliable. The operation of rheometer is simple, and its results are relatively changeless, but it cannot reflect the projects state in reality. The pressure inside the pipe is the flow stream, but vane shear movement is the drag stream. Since they are different boundary conditions, the medium shear patterns are also different. So it caused the results are different[8]. Because the wall slip exists all the time, it is necessary to find the relationships of vane yield stress and curves extension yield stress to predict the yield stress of curve extension.

\section{Pipeline TRAnSPortation Test}

\section{A. Experimental Device}

The dense paste in this test is high concentration coal slurry. Coal slurry consists of coal, waste rocks and clay. Its concentration of solid is about $50 \% \sim 60 \%$, its particle size is less than $0.5 \mathrm{~mm}$.Its wall slip characteristics are related to its concentration, The dense paste wall slip velocity is found to depend on many factors like particle concentration, viscosity and the pipe diameters. The design schematic diagram of test system is as shown in Figure 1.

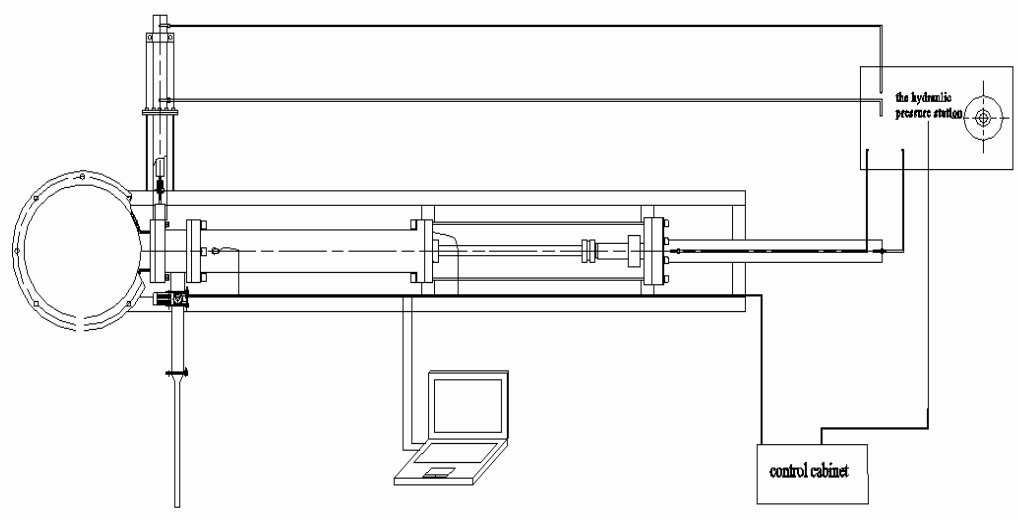

Figure 1. The schematic diagram of the pressure pipe rheological and resistance test system 


\section{B. Experiment Material}

The experiment material is the coal slurry from Tangshan. Its median particle diameter is 9.36um. And $90 \%$ of the whole particle is less than 25.41um. The particle density is $1.76 \mathrm{~g} / \mathrm{cm}^{3}$.It has a high viscosity, high water holding capacity and other characteristics. The particle size distribution is shown in Figure 2.

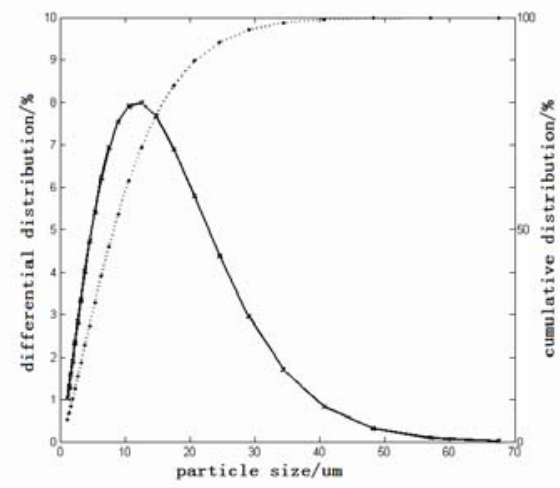

Figure 2. slime particle size distribution

\section{PRINCIPLE}

\section{A. Rheological Curves Extension Yield Stress Principle}

The relationship of the wall shear stress $\tau \mathrm{w}$ and pressure drop $\Delta \mathrm{P}$ correspond the following formula for all non-time-dependent fluid (1).

$$
\tau_{w}=\square p \cdot R / 2 L=\square p \cdot D / 4 L
$$

Its wall shear rate is:

$$
\gamma_{w}=8 v / D
$$

Where, $\tau \mathrm{w}$ is the wall shear stress, $\gamma \mathrm{w}$ is wall shear rate. So if the relationship between $\square p \cdot D / 4 L$ and $8 v / D$ can be got, then it can get a Newtonian fluid constitutive relationship. For non-Newtonian fluid, wall shear rate does not mean $8 v / D$,so $8 v / D$ was called liquidity or imaginary eigenvalues shear rate [6]. Extending the shear stress-rate curves to the stress axis, intersection point is taken as the curves extension yield stress. The extension of the curves means that the balance flow shear stress acting on the material is reduced, the material of the shear rate decreases. When the shear stress reduced to a certain value (when the curve intersects the shear stress axis), the shear rate is zero and the material stops flowing.

\section{B. Vane Yield Stress Testing Theory}

The experiment used Brookfield $\mathrm{R} / \mathrm{S}$ rotational viscometer with ordinary $500 \mathrm{~mL}$ beaker test vessel. A vane spindle is chosen, which has four to six vanes sticking to the axis with the same angles, the structure is shown in Figure $3 \mathrm{a}$. Shear only occurs within the material when the vanes rotate, and slip can be eliminated [9]. According to the measurement conditions of yield stress, the torque at vane surface is replaced by a cylinder with same diameter. Visual impeller and containing materials as a cylindrical rigid body, which withstands the side and top torque while rotating. It can be written as:

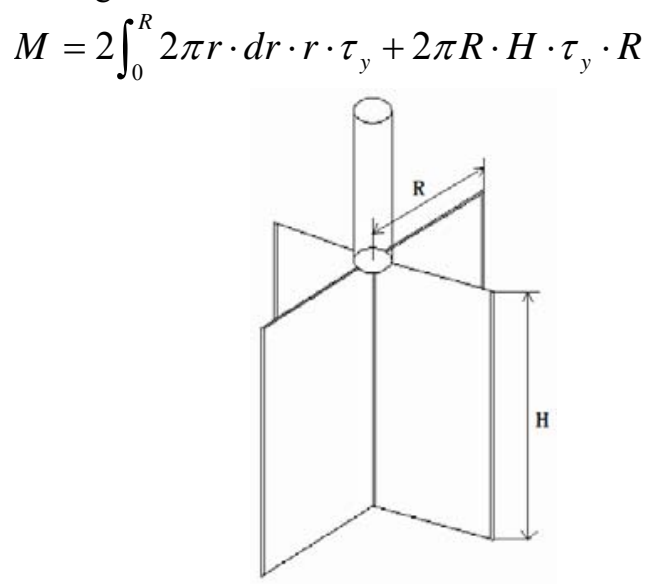

(a)

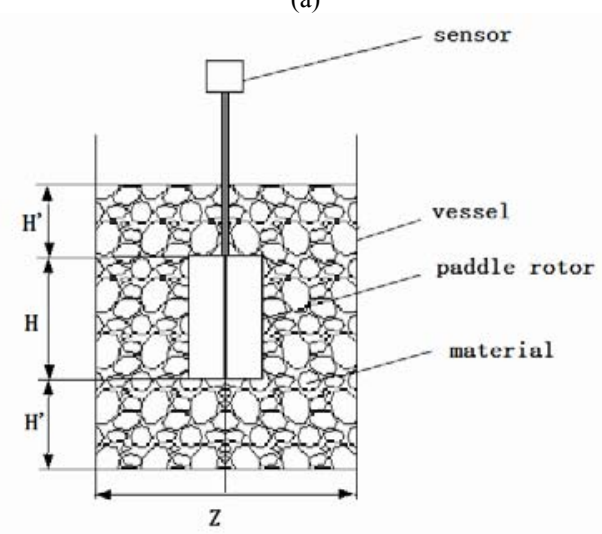

(b)

Figure 3. vane method and structure of the rotor vane test schematic

Experimental equipment is shown in Figure $3 b$.

\section{EXPERIMENTAL RESULTS}

\section{A. Rheological Curve Extension}

By measuring the pressure difference of pipeline materials with different flow rate, the pressure difference is transformed into into wall shear stress at different shear rate. This paper illustrates the coal slime wall slip characteristics by taking examples of transportation in $37 \mathrm{~mm}$ diameter pipes test and data of coal slime transported in different diameters with five volume concentrations. The pipeline diameters are $150 \sim 300 \mathrm{~mm}$ in project sites. The pressure loss decreases with the increase of the diameters. Therefore smaller pipeline delivery pressure has to meet the requirements of large diameter pipe diameter delivery. In this experiment, pipeline diameters are $37 \sim 67 \mathrm{~mm}$, taking $37 \mathrm{~mm}$ diameter pipeline as an example to study in the curve extension method . 


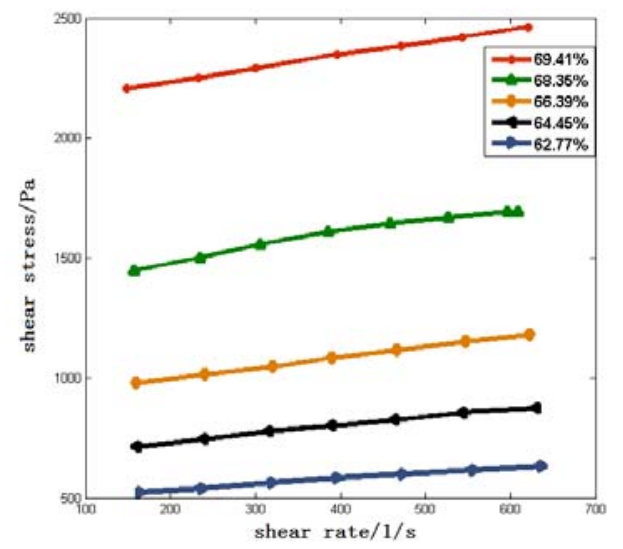

Figure $4.37 \mathrm{~mm}$ diameter flow curves of different concentrations

For each concentration of shear stress and shear rate, the yield stress is plotted as obtained inFigure 4 .

\section{B. Vane Yield Stress Test Results}

Controlling the shear rate, the lower yield stress is, the more gentle the resulting curve is, the more accurate the test result is [2]. After the rotor is inserted in the specified location, with a low shear rate, the rheological parameter detection of materials, the detection time for the 120 s, get the stress - time curve shown in Figure 5.

At higher concentrations, the yield stress curve fluctuates, at low concentrations, the curve is gentle. In general the higher the concentration is, yield stress is bigger. Vane method curve and the extension yield stress curve are approximately same.

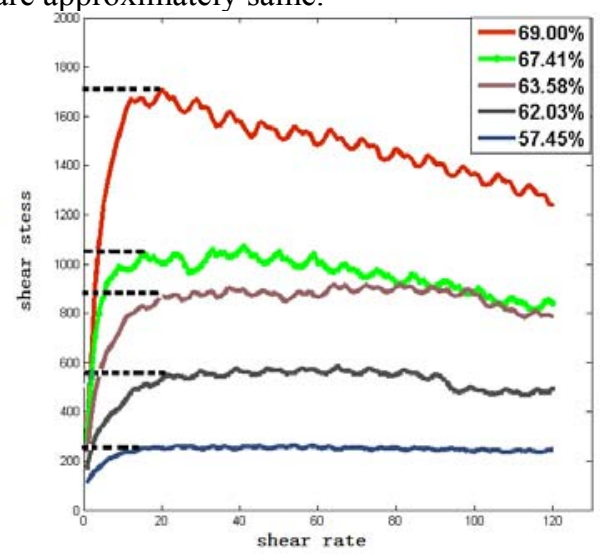

Figure 5. The yield stress curve at different concentrations

\section{Analysis of Two Kinds of Yield Stress}

Since the test results of the curve extension yield stress and diameter of the test pipe have a direct relation, the test results are different when the diameter of the pipe are different. The relation of curve extension yield stress, vane yield stress and concentration is plotted into a curve, and the diameter of the pipe are $37 \mathrm{~mm}, 59.5 \mathrm{~mm}$ and $67 \mathrm{~mm}$, as shown in Figure 6.

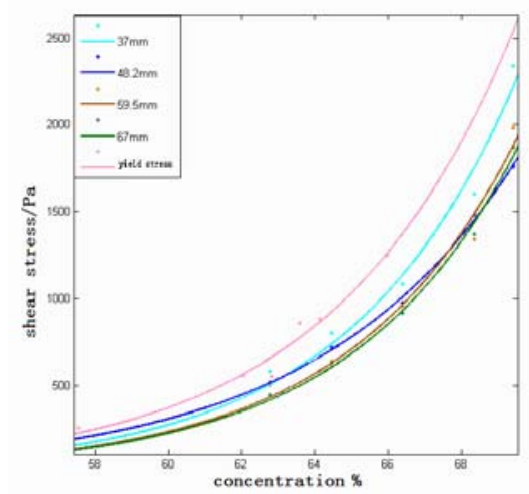

Figure 6. Comparison two types of the yield stress

Within the scope of all kinds of diameter, the yield stress of the material tested by the two methods increase exponentially with the increase of concentration. When the concentration of paste is certain, the pipe flow test yield curve extension stress reduces with the increase of diameter of pipe, but vane yield stress is always bigger than the corresponding pipe flow test curve extension method yield stress, and with the increase of concentration, the difference between them increases, which indicates that the wall slip on curve extension drag reduction effect is more obvious when the concentration is higher. With the increase of the diameter, pipe flow test curve extension yield stress curve gets far away from the vane method yield stress curve. It can be approximated that Vane yield stress is the maximum yield stress on the pipeline project, therefore, the yield stress of the vane can be used to predict the initial yield stress of the paste pipeline flow.

\section{CONCLUSION}

(1) When the thick paste flows in pipe, flow curve is a line. Due to the impact of the pipe wall slip, pipe flow method curve extension yield stress is inaccurate. Yield stress is different in different diameters, and it decreases with the increase of diameter.

(2) The yield stress of vane method and pipe flow method increase exponentially and rapidly as the concentration is increasing, but the data is different.

(3) With a certain concentration and diameter, due to the wall slip effect on the pipeline flow test, vane yield stress is bigger than the curve extension yield stress. And the concentration is higher, the effect of the wall slip is bigger. Therefore, the vane method result can be used as the maximum value and it can guide the design of pipeline system in the engineering application. 


\section{REFERENCES}

[1] Li Chuanxian, Li Qigui. Research on Yielding Behavior of Xinjiang Gelled Crude. Oil and Gas Storage and Transportation. 1999, 18(12): 5 7.

[2] Wu Aixiang, Jiao Huazhe, Wang Hongjiang. Yield stress measurements and optimization of Paste tailings [J]. Journal of Central South University (Science and Technology) , 2013, 44(8):3370-3376.

[3] Bingham E C, Green H P. A plastic material and not a viscous liquid : the measurement of its mobility and yield value [J ]. Proc. Am.Soc1. Test Mater, 1919, 20(2):640 675.

[4] Kraynik, A. M, RE Fluid Standards: Comments on ER Fluid Rheology, Proc, 2nd Int, Conf, ER Fluids 1990.

[5] T. Waugh and D. V. Boger. The measurement and description of the yielding behavior of waxy crude oil. J. of Rheology August 1991, 5(6): $1121 \sim 1156$.
[6] Chang C, Boger D V. The yielding of waxy crude oils [J]. Ind. Eng1. Chem. Res, 1998, 37(4).

[7] Hou Lei, Zhang Jinjun. The Research of Yield Stress of Waxy Crude Oil[J]. Oil and Gas Storage and Transportation.2005, 24(3):5-9.

[8] Liu Gang, Zhang Guozhong. The Development on the Curve extension Characteristics Study for Gelled Crude Oil[J]. Oil and Gas Storage and Transportation,2003,22(1)4 11.

[9] Aaron W.Saak, Hamlin M.Jennings, Surendra P.Shah.The influence of wall slip on yield stress and ciscolastic measurements of cement paste[J]. Cement and Concrete Research,2001,31: 205-212.

[10] Friend P L, Ciavola P, Cappucci S, et al. Biodependent bed Parameters as a proxy tool for sediment stability in mixed habitat intertidal areas[J]. Continental Shelf Research, 2003(23): 1899-1917. 